\title{
Manuel Reyes García Hurtado (ed.), El siglo XVIII en femenino. Las mujeres en el Siglo de las Luces. Madrid: Editorial Síntesis, 2016, 436 págs.
}

El volumen reúne once trabajos que representan una excelente oportunidad de acercamiento a la producción de académicos españoles que en los últimos años, y desde distintas universidades, han venido enriqueciendo con su labor investigativa a la historiografía modernista, y de manera puntual, a la historia de las mujeres. Recorrer los nombres de quienes suscriben cada uno de los capítulos anticipa al lector la calidad de los trabajos que brinda la edición.

Iguales características presenta la valiosa introducción a cargo de García Hurtado, quien ofrece un acertado estado de la cuestión en torno al devenir de la "nueva historia de la mujer" que obtuvo, a su juicio, grandes y sostenidos avances en las últimas tres décadas; representados por un corpus de sólidos trabajos que muestran el auge de las historiografías italiana, francesa, inglesa y norteamericana. En tal sentido, el ámbito académico español también se sumó, a su juicio, a tal producción con indiscutibles resultados en cuando a su calidad y rigor investigativo, aportando en variados aspectos que enriquecen a la historia en general, con un marco conceptual adecuado y metodologías nuevas como resultado de un estrecho contacto con las corrientes renovadoras de las ciencias históricas, en especial de la historia social de cuyos instrumentos analíticos es heredera.

Los trabajos seleccionados representan un ejemplo de la calidad lograda a lo largo de los años, evolución alcanzada desde el momento de inicio que García Hurtado sitúa en la década de 1960, cuando de la mano del feminismo empezaron los intentos por legitimar y valorar la historia de las mujeres, período en que se hizo evidente que la renovación iniciada a partir de Annales tardaba en incluir los problemas relativos a las mujeres; y cuando la historiografía marxista tampoco las incluía, relegándolas al anonimato, a pesar de plantear la necesidad de una historia total desde la óptica de las clases oprimidas. Estas disquisiciones, al igual que la emergencia del concepto de género a partir de 1970 en la reflexión teórica y metodológica, son tratadas de manera cabal y clara por el editor en las páginas iniciales. De este modo, el lector puede obtener un panorama sucinto y actualizado del contexto de producción de los trabajos presentados que aportan a temáticas diversas protagonizadas por mujeres; además de conocer los motivos presentados por García Hurtado para considerar "al siglo XVIII en femenino"; frase que remite entre otras cuestiones a la importancia de los grandes cambios que se sucedieron en las ideas sobre las mujeres durante ese siglo (pp. 19-20).

Las investigaciones escogidas se basaron en fuentes diversas para indagar sobre un objeto de estudio complejo, en principio desde tres vertientes de la historiografía como la historia social, la política y la cultural; ofreciendo a partir de allí, cada uno de ellos, miradas sobre aspectos particulares y diversos que conforman este libro en un rico reservorio de temáticas concernientes a la mujer en la España del siglo XVIII. 
Los capítulos primero, segundo y séptimo son especialmente relevantes desde el punto de vista de la historia de las mujeres, pero además, contribuyen a la historiografía centrada en la familia, con el interés puesto en las mujeres de la realeza y la nobleza. María de los Ángeles Pérez Samper, especialista en Historia Moderna de la Universidad de Barcelona -con particular inclinación por la historia social del poder, de las reinas y de la vida cotidiana en la monarquía española-, ofrece una visión particular sobre las infantas de España. Su interés en indagar el rol de aquellas mujeres al servicio de la monarquía, con una metodología de análisis que combina construcción biográfica de las vidas de distintas mujeres y análisis de fuentes -correspondencia privada y mayormente la Gazeta de Madrid - le permiten a la autora recorrer diversas facetas que involucraba la formación de hijas y hermanas de los monarcas Felipe VI a Carlos IV; su educación, matrimonio, muerte y las implicancias de su imagen femenina en la monarquía española.

María Victoria López- Cordón Cortezo de la Universidad Complutense de Madrid, referente en la historiografía sobre las mujeres, aborda en esta investigación a los personajes femeninos de la corte, en especial su rol político, sus actividades, expectativas, espacio diplomático propio, sus oportunidades e influencias; y la necesaria colaboración que en muchos casos ofrecían a la Monarquía. Para ello se vale del análisis de las disposiciones reales acerca de nombramientos, reglamentos para la familia de la Casa de Rusia, peticiones, testamentos y diversas disposiciones puntuales que regulaban situaciones concretas relativas a las damas de la corte.

El séptimo capítulo a cargo de Gloria Espigado Tocino representa un aporte a la historiografía sobre las mujeres y a las investigaciones dedicadas a la difusión del pensamiento económico, la influencia de la economía política y el surgimiento de instituciones canalizadoras de nuevas ideas y pedagogías reformadoras bajo su influjo, como las Sociedades Económicas de Amigos del País. ${ }^{1}$ De hecho, la autora utiliza en principio el recurso biográfico para introducirnos en la vida de Tomasa Palafox y Portocarrero, hija de María Francisca de Sales y Portocarrero, condesa de Montijo, quien al igual que su hija participó en la Junta de Damas de la Matritense, organización que marcó un hito a favor de las mujeres para su participación en la esfera pública con la creación de dicha Junta de Damas; a partir de la cual podían cumplir además funciones públicas favorables al interés general de la Monarquía. ${ }^{2}$ El trabajo se centra en el siglo XIX, cuando Tomasa ejerció su rol como presidenta de la Junta entre 1817 y 1823; utilizando como fuente las Memorias del organismo que reflejan su gestión y resumen en especial sus vicisitudes como presidenta por falta de fondos en relación a las instituciones benéficas a su cargo como la Inclusa y el Colegio de la Paz. Un trabajo que permite al lector acercarse a lo que la autora denomina la "filantropía ilustrada femenina en tiempos de liberalismo" (p. 266).

\footnotetext{
${ }^{1}$ Sobre el particular pueden consultarse las reflexiones de Jesús Astigarraga en la introducción a Jesús Astigarraga (ed.), The Spanish Enlightenment revisited (Oxford: Voltaire Foundation, University of Oxford, 2015).

2 Para saber más sobre la Junta de Damas y en particular acerca de María Francisca de Sales y Portocarrero véase Virginia Trueba Mira, El claroscuro de las luces: escritoras de la Ilustración española (Madrid: Editorial Montesinos, 2005), 30-35.
} 
El tercer capítulo adscribe a la historia de las emociones. María Luisa Candau Chacón, de la Universidad de Huelva, efectúa un conveniente desarrollo previo en torno al concepto de emoción, que se asemeja a la metodología empleada por la historia conceptual, para explorar luego una serie de experiencias afectivas y pasionales contenidas en diversas fuentes, en especial judiciales, que remiten a diferentes emociones vividas por mujeres durante la modernidad en relación a situaciones como el casamiento, el amor, los celos, el embarazo o el sufrimiento por desamor. Un trabajo que indaga el universo de las emociones, un objeto complejo por la propia subjetividad intrínseca de las emociones, pero que sin embargo Candau Chacón descompone en sus distintas facetas por medio del análisis de fuentes judiciales, correspondencia y otras, de las cuales emergen historias de vida femenina inmersas en un conjunto de discursos, representaciones y prácticas.

La historiografía de la familia es nuevamente enriquecida en los capítulos cuarto y quinto. María José de la Pascua Sánchez, investigadora de la Universidad de Cádiz que ha aportado en los últimos años en cuestiones como los conflictos y los afectos dentro de la historia de las mujeres y de la familia, ofrece una aproximación al tema de las mujeres solas, familias a cargo de esas mujeres o familias de mujeres solas sin tutela masculina en el siglo XVIII hispánico. Se trata de un colectivo femenino cuya cantidad la autora revela como muy numerosa durante el siglo, tanto en España como en Europa; análisis al que agrega el caso particular de Cádiz. Su trabajo de indagación se realizó mayormente a partir de requisitorias de Indias frente a los tribunales, aunque antes de presentar sus apreciaciones, de la Pascua Sánchez ofrece valiosas referencias a la historiografía del siglo XX sobre el estudio de la familia, vinculada a la demografía y al análisis económico, que en los últimos años se reorientó hacia una concepción de la familia sobre relaciones de poder, desigualdad entre sexos, en suma, como ámbito de conflictos. En ese contexto, la autora enfatiza la importancia del derecho y del patriarcado interactuando ambos en la vida familiar, para detenerse luego en esas "otras familias" (p. 169) al margen del modelo marital que suponía la existencia de un hombre al que las mujeres debían obediencia. Para refrendar su análisis, de la Pascua Sánchez se apoya en información estadística de distintas ciudades de Europa, índices que contemplan porcentajes de viudas sobre la población total, de población soltera $\mathrm{u}$ hogares con jefatura femenina, entre otros.

En el capítulo siguiente, María José Pérez Álvarez, académica de la Universidad de León y especialista en los espacios de la montaña leonesa durante la Modernidad con particular atención en las estructuras familiares, demográficas y socioeconómicasacerca su mirada a las mujeres que habitaron esos territorios de Montaña durante el siglo XVIII. Su aproximación se detiene en los comportamientos matrimoniales y el protagonismo femenino al frente de unidades familiares. Con auxilio de la estadística, al igual que el anterior trabajo, la autora analiza a las mujeres por grupos etarios, según su estado civil, su ejercicio de la jefatura hogareña, la representación de la jefatura femenina en los distintos grupos de edad y las tipologías de corresidencia de mujeres jefas de hogar (solitarias, nuclear, sin estructura o compleja). Todo ello, resultado de un cuidado análisis de libros de familia del Catastro del marqués de Ensenada, padrones elaborados en el concejo de Laciana y otras fuentes que le permitieron señalar ciento sesenta unidades domésticas y efectuar comparaciones con investigaciones 
concernientes a otros espacios. El trabajo le permite a la autora poner en evidencia que no obstante vivir solas, estas mujeres solían buscar a un pariente para recibir asistencia al final de sus días, a cambio de su herencia, con acuerdos previos que pasmaban en escrituras de donación, de dote o testamento. Para aquellas que no tenían nada que ofrecer, la investigación indica el valor de estos casos para mostrar la puesta en marcha de verdaderos mecanismos de solidaridad, vecinales o familiares.

Los capítulos seis, ocho, nueve y diez nutren por su parte a la historia cultural. En el primero de ellos, Mónica Bolufer Peruga, reconocida historiadora de las mujeres de la Universidad de Valencia, se aboca a los viajes de mujeres; desde los relatos de mujeres viajeras, las traductoras y las lectoras de escritos de ese tipo. Sobre tal universo que permitía ampliar los horizontes mentales de las mujeres, Bolufer Peruga aclara que en comparación con la producción de relatos en el resto de Europa, fueron pocas las escritoras de viajes españolas que trascendieron, más allá de los relatos de María Agustina Ramona de Siles y Cuenca, Isabel Parreño Arce, María Rosa Gálvez o Rita Barrenechea, a quienes analiza en sus particularidades y contextos de producción. La autora remarca la importancia de las traductoras españolas de libros de viajes que demostraban su interés por un género y temática propios de la época; sujetos a lecturas y apropiaciones diversas (p. 230) y campo donde destacaron mujeres como Josefa Amar, quien además veía en la literatura de viajes un hábito intelectual fundamental como propuesta pedagógica para las mujeres. ${ }^{3}$ Analiza, además, las particularidades de traducciones como las de María Josefa Luzuriaga o María Romero Masegosa y Cancelada; mujeres que con sus trabajos ampliaban el universo de opciones disponibles para las potenciales lectoras que desde sus hogares podían enriquecer sus opciones de lectura e imaginación, para comprender el funcionamiento de sociedades y lugares distantes, ajenos a su realidad. En todo caso, tanto el viaje leído como vivido es una posibilidad que la autora muestra como una experiencia propia del siglo XVIII femenino.

Isabel Morant Deusa, reconocida especialista en historia Moderna y de las mujeres de la Universidad de Valencia, analiza los usos de la novela formativa en el siglo XVIII, con especial atención a la obra del novelista inglés Richardson y su recepción en España. ${ }^{4}$ A pesar de que la autora aclara que la novela moderna tuvo en España un desarrollo tardío y ejerció una influencia menor en la difusión del discurso ilustrado, no deja de remarcar la pretensión existente de que las lectoras encontrasen en la novela una guía práctica para formar sus valores y conductas que debían tener acordes a su sexo femenino, como solteras, casadas y madres (p.284). Enfatiza el papel de la novela en los cambios en la representación social de la moral femenina y de las relaciones de los sexos; en la construcción de las identidades y las conciencias femeninas. En el caso puntual de España y la introducción de Richardson como una de las opciones de lectura, Morant Deusa analiza cómo el prólogo a la edición castellana sirvió para vehiculizar la idea del origen divino de la moral y la pureza junto a la

\footnotetext{
${ }^{3}$ María Victoria López-Cordón Cortezo incluida también en la compilación es autora de un libro dedicado a la figura de Josefa Amar y Borbón. María Victoria López-Cordón Cortezo, Condición femenina y razón ilustrada: Josefa Amar y Borbón (Zaragoza, Prensas Universitarias de Zaragoza, 2005). 4 Refiere a los elogios que Diderot manifestara al momento de la muerte del novelista en 1761 y en la particular la recepción en España de su novela Pamela publicada en castellano por primera vez en 1794.
} 
castidad como valores exigidos a toda mujer, que será reconocida socialmente por tales cualidades. Un trabajo que aporta a la historiografía de las mujeres, pero también a aquella dedicada a los usos de la literatura en general durante el siglo XVIII.

En el noveno capítulo, Ana Vega Toscano (Universidad de Cádiz), recurre a la música en el espacio femenino; análisis que le permite aportar a la hipótesis de visibilidad que las mujeres alcanzaron durante el siglo en los espacios públicos, en este caso a través del rol de mecenas que algunas de ellas pudieron asumir. Investigación que, además de la historiografía sobre mujeres, nutre a lo que la autora describe como las "antiguas historias oficiales de la música", que no reflejaron a la práctica musical como una de las actividades más características del espacio femenino en la modernidad occidental (p. 293). El desarrollo de la autora, con un recorrido por la educación femenina y la aparición del "maestro de música", el mecenazgo musical, las mujeres y su relación con la ópera o la creación musical, constituye un valioso aporte tanto para la historia social de la música como para los estudios de género.

El último trabajo que hemos clasificado como de historia cultural dentro de este libro debe su autoría a Inmaculada Urzainqui Miqueleiz, especialista en literatura española de la Universidad de Oviedo, quien fija su atención en la prensa española a la que considera como instrumento modelador de la conducta femenina; en un contexto en el cual periodismo e Ilustración fueron a su juicio indisociables en toda Europa. La investigación evidencia en su desarrollo cómo un horizonte de pautas y sugerencias, en función de un conjunto de valores y bajo formatos o discursos diversos, se proporcionó a las mujeres por medio de la prensa como género comunicativo de la vanguardia ilustrada (p. 321). Para Uzainqui Miqueleiz el objetivo era que las mujeres tomasen conciencia de su identidad, de cómo vivir y qué hacer dentro de programa de regeneración y progreso general. Con recurso a fuentes como El Censor, El Pensador, El argonauta español o Diario de Madrid, entre otras publicaciones periódicas, la autora expone cómo el discurso formativo para el público femenino se introducía en la sociedad española bajo formatos varios como la prensa de ideas o informativa, reseñas y comentarios de libros o piezas teatrales, las publicaciones económicas o científicotécnicas, o bien las poesías, anécdotas y biografías con valor ejemplarizante. Su lectura resulta fundamental por su aporte a la historiografía de las mujeres pero además por profundizar en la historia de la prensa, uno de los baluartes indiscutidos del periodo de las Luces.

Las últimas páginas del libro corresponden al trabajo más extenso de la obra a cargo del editor, García Hurtado, especialista en historia del ejército español de la Universidad de A Coruña, quien presenta un tópico poco abordado por la historiografía sobre las mujeres hasta el momento: la relación de éstas con el universo de los militares. Se pregunta si existió alguna posibilidad de vinculación para las mujeres con lo militar, más allá de ser esposa "de" un miembro del ejército o la armada; cuál era la imagen que se ofrecía de ellas a los militares y de qué manera se facilitaba, impedía o limitaba la relación entre ambos (p.328). Para lograr su objetivo García Hurtado recurrió a fuentes como los tratados morales de autores religiosos o militares destinados a soldados para analizar cuál era la imagen femenina difundida por medio de ellos. Utilizó en segundo lugar ordenanzas relativas a situaciones consideradas ilícitas en relación con ellas como 
la bigamia, el adulterio, el matrimonio sin autorización o la convivencia sin casamiento. Apeló al análisis de regulaciones y discursos sobre las mujeres militares, sobre su capacidad natural y legal para el ejercicio de las armas; sin dejar de incluir ejemplos presentes en la modernidad española como María Pita en La Coruña o Justina de Aragón en Zaragoza, entre otras. Por último, analizó la política asistencial pensada para las mujeres esposas, hijas o hermanas de militares fallecidos, por medio de socorros puntuales o los monte píos (el primer reglamento fue expedido en Nápoles en 1753), que reflejaron una solidaridad desigual hacia las mujeres, reflejo de los lineamientos de jerarquización existentes en la propia estructura militar. Un trabajo exhaustivo en su análisis de numerosas fuentes, novedoso para la historiografía de las mujeres y que aporta de manera sólida al enriquecimiento de la historiografía sobre el ejército español moderno.

Un libro de necesaria lectura por muchos motivos, pero sobre todo por tres que resultan fundamentales. Por referir, en primer lugar, al siglo XVIII español, clave en cuanto a los cambios y percepción colectiva respecto de la mujer; segundo, por aportar a la historiografía de las mujeres y de género desde diferentes enfoques, aspectos y metodologías de abordaje; y por último, por ofrecer a los lectores una actualización sobre la labor que cada uno de los especialistas reunidos viene efectuando, constituyendo su mera mención sello indiscutido de calidad académica en la historiografía española de nuestros días.

Adriana N. Milano

Universidad Nacional de Rosario, Argentina

adria_milano@yahoo.com.ar

Fecha de recepción: 26 de julio de 2018.

Fecha de aceptación: 22 de octubre de 2018.

Publicación: 31 de diciembre de 2018.

Para citar este artículo: Adriana N. Milano, "Manuel Reyes García Hurtado (ed.), El siglo XVIII en femenino. Las mujeres en el Siglo de las Luces. Madrid: Editorial Síntesis, 2016, 436 págs.”, Historiografías, 16 (julio-diciembre, 2018): 136-141. 